\title{
Brasagem de Aços Inoxidáveis Martensíticos Utilizando Pasta à Base de Níquel em Forno a Vácuo
}

\author{
Vicente da Rocha Carvalho ${ }^{1}$ (D) , Ivan Guerra Machado ${ }^{1}$ (D) \\ ${ }^{1}$ Universidade Federal do Rio Grande do Sul - UFRGS, Laboratório de Soldagem \& Técnicas Conexas, Programa de Pós-graduação em Engenharia de Minas, \\ Metalúrgica e de Materiais - PPGE3M, Porto Alegre, RS, Brasil.
}

Como citar: Carvalho VR, Machado IG. Brasagem de aços inoxidáveis martensíticos utilizando pasta à base de níquel em forno a vácuo. Soldagem \& Inspeção. 2020;25:e2508. https://doi.org/10.1590/0104-9224/SI25.08

\begin{abstract}
Resumo: Aços inoxidáveis martensíticos são largamente utilizados pela indústria cuteleira, especialmente para produtos que tem contato com alimento. Nesta aplicação algumas propriedades são importantes, como resistência à corrosão, tenacidade e retenção do fio - esta última fortemente influenciada pela limpeza do aço. No entanto, aços com tais propriedades tendem a ser caros e possuem baixa soldabilidade. O objetivo deste trabalho é desenvolver a união por brasagem entre os aços inoxidáveis martensíticos Uddeholm Elmax e DIN EN 1.4110, a fim de usar o Uddeholm Elmax apenas na região do fio, reduzindo custos. Uma pasta classificada como DIN EN ISO 3677 B-Ni60CrPSi-980/1040 foi utilizada como metal de adição. Os parâmetros testados foram: tempo de brasagem (5, 10 e $30 \mathrm{~min})$ e temperatura de brasagem $\left(1080,1100\right.$ e $\left.1120^{\circ} \mathrm{C}\right)$. Os corpos de prova foram submetidos a ensaio de tração e analisados por microscópio óptico e MEV, além de medições de dureza e microdureza. Os maiores valores para o ensaio de tração foram encontrados nas amostras brasadas com tempo de $10 \mathrm{~min}$ e temperatura de $1120^{\circ} \mathrm{C}$. Foi possível brasar os materiais de acordo com o objetivo deste trabalho.
\end{abstract}

Palavras-chave: Brasagem; Aço inoxidável martensítico; Metal de adição base níquel; Têmpera.

\section{Brazing of Martensitic Stainless Steels Using Nickel Based Paste in Vacum Furnace}

\begin{abstract}
Martensitic stainless steels are widely used in the cutlery industry especially for food contact products. In this application, some properties are important like the corrosion resistance, toughness and edge retention - the latter strongly influenced by the cleanliness of the steel. However, steels with such properties tend to be expensive materials and have low weldability. The aim of this work is to develop a brazed joint between martensitic stainless steels Uddeholm Elmax and DIN EN 1.4110 in order to use the Uddeholm Elmax only in the cutting edge, reducing costs. A paste classified as DIN EN ISO 3677 B-Ni60CrPSi-980/1040 was used as filler metal. The tested parameters were: dwell time (5, 10 and $30 \mathrm{~min}$ ) and brazing temperature $\left(1080,1100\right.$ e $\left.1120{ }^{\circ} \mathrm{C}\right)$. The samples were submitted to tensile test as well as light microscope and SEM analysis, in addition to hardness and microhardness measurements. The highest values for the tensile test were found for the $10 \mathrm{~min}$ and $1120^{\circ} \mathrm{C}$ brazed samples. It was possible to braze the materials according the objective of this work.
\end{abstract}

Key-words: Brazing; Martensitic stainless steel; Nickel based filler metal; Quenching.

\section{Introdução}

A brasagem, por não fundir os metais base $(\mathrm{MB})$, apresenta algumas vantagens em relação à soldagem, especialmente no caso de aços inoxidáveis martensíticos. Estes aços são frequentemente usados na indústria cuteleira que tem, por vezes, interesse em unir mais de um aço na mesma faca. Desta forma, torna-se interessante juntar por brasagem um aço que tenha excelente desempenho quando aplicado em facas com outro aço popular nesta área e cujo processamento já é dominado pela indústria.

Fornos a vácuo são cada vez mais utilizados para têmpera e outros processos que dependam de aquecimento. Como operam com ausência de oxigênio, as peças saem do forno sem a camada de óxido típica do tratamento térmico em outros equipamentos, além de não haver necessidade de fluxo no processo de brasagem. Estes fornos tem também uma grande flexibilidade com o ajuste das rampas de aquecimento e rápido resfriamento para cada caso, permitindo que a têmpera e a brasagem possam ser executadas num mesmo processo e facilitando ciclos térmicos que evitem a formação de fenômenos prejudiciais como tensões na junta, por exemplo [1].

Há muitos anos já são executadas brasagens utilizando fornos a vácuo para a união dos materiais. Muitas vezes, estes processos incluem a brasagem propriamente dita em um estágio e, logo após, ainda dentro do forno, é feito o tratamento

Recebido: 21 Nov., 2019. Aceito: 27 Fev., 2020

E-mails: vicente.carvalho@tramontina.net (VRC), welder@ufrgs.br (IGM)

Este é um artigo publicado em acesso aberto (Open Access) sob a licença Creative Commons Attribution Non-Commercial, que permite uso, distribuição e reprodução em qualquer meio, sem restrições desde que sem fins comerciais e que o trabalho original seja corretamente citado. 
térmico dos materiais base. Desta maneira, se executa em forno a vácuo a brasagem e têmpera de aços inox martensíticos no mesmo ciclo de aquecimento [2-6].

Para este caso em que a brasagem é feita concomitante com o tratamento térmico dos metais base, é importante notar que um metal base mais dúctil pode aumentar a resistência à fadiga da junta, pois a maior ductilidade retarda a propagação de trincas por fadiga, além de suportar trincas de tamanho crítico maiores [7].

Outro ponto de atenção para uma junta brasada através da rota descrita acima é com relação às variações dimensionais dos materiais em função da temperatura. Esta variação vem principalmente de dois fatores, considerando dois aços distintos a serem brasados:

1. Uma grande diferença dimensional é devido às transformações metalúrgicas que ocorrem nos metais base durante a têmpera. Sabe-se que na formação da martensita há expansão volumétrica do material e que esta expansão se dá em uma temperatura diferente para cada aço. Assim, durante o resfriamento, cada aço irá passar por estas variações dimensionais em momentos distintos, gerando tensões na junta brasada [8];

2. A segunda fonte de variação ocorre em menor grau, através da diferença de coeficientes de expansão térmica entre os dois materiais. Para dois aços inoxidáveis martensíticos, esta diferença é muito pequena [9].

Portanto, é requerido ao metal de adição (MA) que seja suficientemente deformável (elástica ou plasticamente) a ponto de manter a junta brasada íntegra mesmo após esta expansão volumétrica desigual entre os três materiais envolvidos na junta. É importante ainda notar que não se faz referência ao tamanho ou comprimento desta junta. Porém, obviamente, juntas com maior comprimento serão mais suscetíveis a problemas desta natureza do que aquelas mais curtas. Assim, o tamanho das juntas brasadas constitui também importante parâmetro durante o projeto da mesma [10].

Estes fenômenos relacionados à expansão térmica dos materiais podem gerar trincas na junta de forma a induzir efeitos negativos na mesma, exigindo um resfriamento mais brando ou controlado até uma temperatura suficientemente baixa para evitar redução da resistência da junta [6].

Temperaturas mais altas podem gerar menor teor de porosidades. Para metais de adição de base níquel, uma temperatura de brasagem muito próxima à linha solidus pode ocasionar o baixo molhamento no metal base gerando assim vazios na junta. Temperaturas mais altas aumentam a molhabilidade destes metais no aço martensítico [11].

Este efeito da temperatura sobre a molhabilidade também foi observado para metais de adição de base níquel sobre aço inoxidável martensítico, sendo evidenciado um bom molhamento do metal de adição para temperaturas acima de $1025^{\circ} \mathrm{C}$ [12].

Apesar disto, conforme experimentos realizados por Chakraborty et al. [13], é possível formar juntas brasadas livres de porosidades mesmo sem a utilização de fornos a vácuo, apenas com atmosferas inertes de argônio. Neste caso, temperaturas de 60 graus acima da linha solidus do metal de adição já foram suficientes para juntas sem porosidades.

Aços inoxidáveis tendem a apresentar baixa molhabilidade para metais de adição, principalmente aqueles que não tem níquel na sua composição. A fim de contornar este problema, alguns autores que trabalham com estes materiais utilizam filmes de níquel depositados sobre os materiais base, mantendo a superfície limpa e livre de oxidações. Assim, evita-se o problema dos filmes de óxido de cromo que seriam naturais nos aços inox e incrementa-se a molhabilidade [3,14,15].

Esta prática de deposição de filmes de níquel pode ser vantajosa em relação à molhabilidade conferida ao conjunto brasado, melhorando a penetração do metal de adição na junta. Porém, acarreta em mais uma etapa de fabricação, onerando o processo em tempo e custo caso este venha a ser reproduzido em escala industrial. Processos de deposição de filmes metálicos por células galvânicas são também indesejados devido ao impacto ambiental que podem gerar [3].

Desta forma, torna-se interessante avaliar o papel do níquel não apenas como filme depositado no material base, mas como componente do metal de adição a fim de aumentar a molhabilidade e consequentemente a resistência mecânica da junta brasada. Muitos metais de adição são compostos principalmente por níquel e as temperaturas de brasagem são também compatíveis com processos utilizando aços inox austeníticos e - em alguns casos - martensíticos também. Ainda, o níquel contido no metal de adição pode difundir e reforçar a junta brasada na forma de solução sólida nos materiais base [14].

A família dos metais de adição de base níquel tem faixa de temperatura adequada para utilização concomitante com têmpera de aços martensíticos. Além disto, tem variedade de composições químicas mais extensa do que os metais de adição de base prata e são excelentes para resistência a corrosão - uma propriedade geralmente desejada quando se utiliza aços inox. Por fim, sua composição o torna excelente para utilização em fornos a vácuo (não há vaporização de metais), o que faz com que esta família seja muito popular para este método de brasagem [16].

No processo de brasagem o metal de adição tem que inicialmente fluir para o interior da folga e a partir daí a difusão atômica une os materiais. Portanto é fácil entender que o tempo mínimo de processo é aquele necessário que o metal de adição ocupe o espaço entre os materiais base. Tempos tão pequenos quanto 5 minutos já podem ser suficientes para o preenchimento da folga para alguns casos, obviamente dependendo sempre da temperatura e do metal de adição em questão [8,12].

Além dos materiais envolvidos na brasagem, um parâmetro importante é a temperatura, que deve ser abordado com atenção. É sabido que maior energia (calor) possibilita maior difusão, visto que os átomos terão maior mobilidade em maiores 
temperaturas. Portanto, é esperado que para um tempo admissível de processo, exista uma temperatura mínima para que ocorra a difusão - e consequentemente a brasagem. Seguindo este raciocínio e considerando apenas variações na temperatura, o aumento desta aumenta também a profundidade da camada difundida do metal de adição no metal base [15].

Um cuidado que deve ser tomado com juntas brasadas em aços inox martensíticos diz respeito às interações que podem resultar do contato entre metais base e metal de adição. Quando a junta está em alta temperatura, difusão atômica ocorre nas superfícies molhadas pelo metal de adição e neste momento pode se dar a ocorrência de compostos intermetálicos frágeis [17].

Estes compostos intermetálicos frágeis podem ser responsáveis por nuclear e iniciar trincas durante tensão, propagar estas trincas e acabar causando a falha da estrutura mesmo para casos onde os metais base inicialmente possuem adequada ductilidade. Mesmo processos conduzidos a menores temperaturas - da ordem de $500{ }^{\circ} \mathrm{C}$ - podem gerar a formação dos danosos compostos intermetálicos frágeis. Por exemplo, a formação de nitretos de ferro (FeN ( $_{3}$ em aço inox martensítico durante brasagem em forno a vácuo, conforme estudos já realizados [4].

Como a difusão atômica que ocorre durante a brasagem é um processo dependente de tempo e temperatura, otimizar ambos parâmetros é primordial para obtenção da junta brasada de boa qualidade. Diversos trabalhos versam sobre combinações entre tempos e temperaturas. No entanto, pela natureza dos fenômenos envolvidos, a determinação ideal destes parâmetros para o processo varia grandemente, sendo necessário testes que caracterizem a melhor combinação das variáveis [18].

Ainda sobre os parâmetros tempo e temperatura, é importante que se parta de uma estimativa aproximada da situação ideal de forma que os testes de caracterização sejam apenas confirmações de expectativas baseadas nas variáveis do processo, entre eles principalmente composição química dos materiais base, metal de adição, folga da junta, equipamento e ambiente no qual será executada a junta [14].

Por um lado, uma maior difusão pode induzir a melhor adesão. No entanto, existe uma temperatura na qual passa a haver um efeito nocivo da difusão do metal de adição no metal base, levando à menor resistência mecânica da junta brasada. Diversos autores investigaram este fenômeno e evidenciaram que, normalmente, a resistência mecânica da junta brasada passa a diminuir a partir do momento em que se formam compostos intermetálicos frágeis ou mesmo quando existe a penetração intergranular do metal de adição no metal base $[3,8,14,19]$.

Existem ainda evidências de que o tamanho destes compostos intermetálicos frágeis esteja relacionado à resistência mecânica da junta. Quanto maior forem os compostos frágeis, menor a resistência [20].

Por outro lado, em outros casos, o aumento da temperatura produz uma junta mais resistente. Em brasagem de aços martensíticos com metais de adição de base níquel pode ocorrer a formação de fases frágeis e contínuas, principalmente aquelas formadas por redutores de ponto de fusão do metal de adição, tais como boro, silício e fósforo. Para temperaturas mais altas, estas fases, embora persistam, deixam de ser contínuas e aparecem em menor proporção ao longo da região brasada, aumentando assim a resistência da junta para temperaturas maiores. Apesar do efeito positivo do aumento da temperatura neste caso, compostos intermetálicos frágeis vão sempre existir na região da junta [18,21].

Estes compostos frágeis que reduzem a resistência da união por brasagem tendem a ser menos deletérios para maiores temperaturas já que a difusão adequada destes elementos proporcionam uma microestrutura menos frágil e portanto com ótima resistência à tração [18,22,23].

Assim, entende-se que os compostos intermetálicos podem ter efeitos antagônicos na resistência da junta brasada: por um lado a tornam mais suscetível a trincas e rompimento frágil, porém, contribuem para o aumento da resistência da junta brasada.

Apesar de todos os dados teóricos para estimar os parâmetros de processo, experimentos são imprescindíveis para determinar as condições ideais de um dado projeto de junta brasada, tamanha é a sua complexidade e consequente imprevisibilidade. Ainda há falta de compreensão total dos fenômenos envolvidos na brasagem [24]. Desta forma, o presente trabalho visa investigar a influência dos parâmetros tempo e temperatura na brasagem dos aços Uddeholm Elmax e DIN EN 1.4110 utilizando pasta de base níquel, além de verificar a possibilidade de executar brasagem e têmpera dos materiais no mesmo ciclo térmico.

\section{Materiais e Métodos}

Neste trabalho foi utilizado o aço inoxidável martensítico DIN EN 1.4110 largamente utilizado na indústria cuteleira, além de aplicações que vão desde a área da saúde à construção mecânica.

$\mathrm{O}$ aço em questão é recebido laminado em bobinas com espessura de $2,4 \mathrm{~mm}$, recozido e (apenas para referência) possui tensão de escoamento $(0,2 \%)$ de 315 a $515 \mathrm{~N} / \mathrm{mm}^{2}$.

Tabela 1. Composição química dos metais base e metal de adição* [25].

\begin{tabular}{ccccccccccc}
\hline & $\mathrm{C}$ & $\mathrm{Cr}$ & $\mathrm{Mo}$ & $\mathrm{Mn}$ & $\mathrm{Si}$ & $\mathrm{V}$ & $\mathrm{S}$ & $\mathrm{P}$ & $\mathrm{Ni}$ \\
DIN EN 1.4110 & $\mathbf{0 , 4 5}$ & $\mathbf{1 4 , 6 1}$ & $\mathbf{0 , 5 3}$ & $\mathbf{0 , 3 7}$ & $\mathbf{0 , 5 2}$ & $\mathbf{0 , 1 5}$ & $\mathbf{0 , 0 0 8}$ & $\mathbf{0 , 0 2}$ & $\mathbf{0 , 1 9}$ \\
Elmax & $\mathbf{1 , 4 4}$ & $\mathbf{1 8 , 3 2}$ & $\mathbf{0 , 8 2}$ & $\mathbf{0 , 3 3}$ & $\mathbf{0 , 7 0}$ & $\mathbf{2 , 9 2}$ & $\mathbf{0 , 0 1}$ & $\mathbf{0 , 0 2}$ & $\mathbf{0 , 2 8}$ \\
Metal de adição & - & $\mathbf{2 9}$ & - & - & $\mathbf{4}$ & - & - & $\mathbf{6}$ & Restante \\
\hline
\end{tabular}

*Para a composição química do metal de adição utilizou-se valores informados pelo fabricante. 
Escolheu-se o aço fora de norma e patenteado Uddeholm Elmax para ser brasado com o material citado acima. O Elmax é similar ao DIN EN 1.4125 (ou AISI 440C), porém com teor mais alto de ligas. O carbono significativamente mais alto, cromo e molibdênio no extremo superior das faixas, além de alta quantidade de vanádio. Fabricado por metalurgia do pó para ser aplicado como aço ferramenta em moldes de injeção, além de aplicações especiais na indústria de alimentos, onde é exigido uma boa resistência à corrosão aliada a uma alta resistência à abrasão. Esta segunda aplicação é uma grande vantagem para a indústria cuteleira frente aos demais aços convencionais do mercado.

Este aço é fornecido em chapas laminadas e levemente recozidas com dureza de aproximadamente 250 Brinell. A espessura da chapa de Elmax é de $2,0 \mathrm{~mm}$.

Para referência, a tensão de escoamento $(0,2 \%)$ divulgada pelo fabricante é de aproximadamente $2000 \mathrm{~N} / \mathrm{mm}^{2}$, por volta de 5 a 6 vezes o valor do DIN EN 1.4110.

Como metal de adição utilizou-se a pasta de brasagem B-Ni60CrPSi-980/1040 (DIN EN ISO 3677). Esta é uma pasta de base níquel para brasagens de alta temperatura.

A composição química dos materiais empregados pode ser vista na Tabela 1.

Foram confeccionados corpos de prova (CP) de tração similares aos da norma ASME QB-462.1 (a), porém com dimensões modificadas a fim de que ficassem compatíveis com as dimensões da máquina de tração e os objetivos deste trabalho.

Os metais base foram desengraxados, lixados empregando granulação 1000 e limpos com álcool isopropílico. Foram então ajustados em um suporte (conforme Figura 1) com folga de $0,10 \mathrm{~mm}$. A distância entre os materiais foi assegurada pelo posicionamento de um calibrador de folga entre os metais base no momento de sua fixação. A pasta de brasagem foi então colocada na parte externa da folga e o conjunto levado ao interior do forno a vácuo.

A avaliação dos efeitos do tempo e temperatura na resistência do conjunto brasado foi executada mantendo a folga de $0,10 \mathrm{~mm}$.

Após a brasagem e têmpera os corpos de prova foram revenidos a $260^{\circ} \mathrm{C}$.

As amostras testadas foram submetidas a um processo em forno a vácuo que variou conforme parâmetros estipulados, sendo estes: tempo e temperatura de brasagem, conforme Tabela 2.

Na Figura 2 pode-se visualizar o ciclo ao qual as amostras foram submetidas em forno a vácuo.

A primeira parte do ciclo térmico, até $300^{\circ} \mathrm{C}$, foi feita em vácuo de $8 \times 10^{-5}$ bar. Seguindo o procedimento padrão do forno, o aquecimento posterior foi feito com auxílio de nitrogênio até $780{ }^{\circ} \mathrm{C}$. A partir deste ponto, se fez novo vácuo e assim permaneceu até o momento da têmpera.

Depois da etapa a $780^{\circ} \mathrm{C}$, foi empregada taxa de aquecimento de $12{ }^{\circ} \mathrm{C} / \mathrm{min}$ até $900{ }^{\circ} \mathrm{C}$. Entre $900{ }^{\circ} \mathrm{C}$ e a temperatura de brasagem, a taxa de aquecimento foi aumentada para aproximadamente $25^{\circ} \mathrm{C} / \mathrm{min}$.

Os materiais foram mantidos na temperatura de brasagem $\left(1080,1100\right.$ ou $\left.1120^{\circ} \mathrm{C}\right)$ para os tempos de 5,10 e 30 minutos. Logo após, os corpos de prova foram resfriados em atmosfera de nitrogênio com pressão de 5 bar e $50 \%$ da potência do ventilador do forno a vácuo TAV modelo H6-S.

$\mathrm{O}$ código atribuído aos $\mathrm{CP}$ está conforme as respectivas condições de processo, sendo os dois primeiros algarismos para o tempo em minutos, seguido de três algarismos indicando a temperatura (para centena, dezena e unidade, em graus Celsius) e os últimos dois para a folga $(0,10 \mathrm{~mm}$ para todos $\mathrm{CP})$.

Tabela 2. Condições de brasagem para as amostras testadas.

\begin{tabular}{|c|c|c|c|}
\hline Parâmetro & Código CP & Tempo & Temperatura \\
\hline & 05.100 .10 & $5 \mathrm{~min}$ & \\
\hline \multirow[t]{3}{*}{ Tempo } & 10.100 .10 & $10 \mathrm{~min}$ & $1100^{\circ} \mathrm{C}$ \\
\hline & 30.100 .10 & $30 \mathrm{~min}$ & \\
\hline & 10.080 .10 & & $1080^{\circ} \mathrm{C}$ \\
\hline \multirow[t]{2}{*}{ Temperatura } & 10.100 .10 & $10 \mathrm{~min}$ & $1100^{\circ} \mathrm{C}$ \\
\hline & 10.120 .10 & & $1120^{\circ} \mathrm{C}$ \\
\hline
\end{tabular}

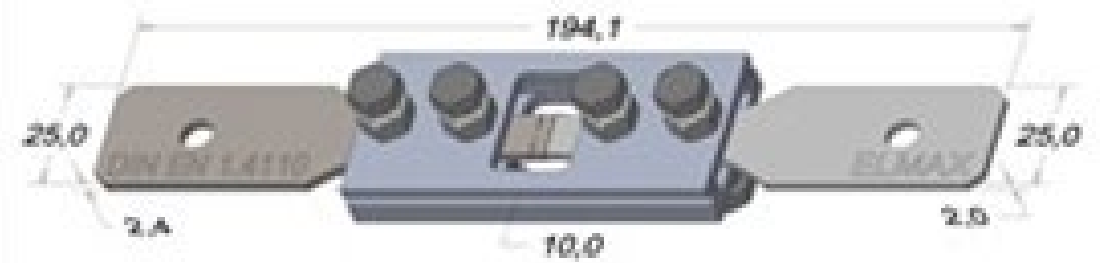

Figura 1. Representação esquemática dos $\mathrm{CP}$ posicionados no suporte para brasagem. 


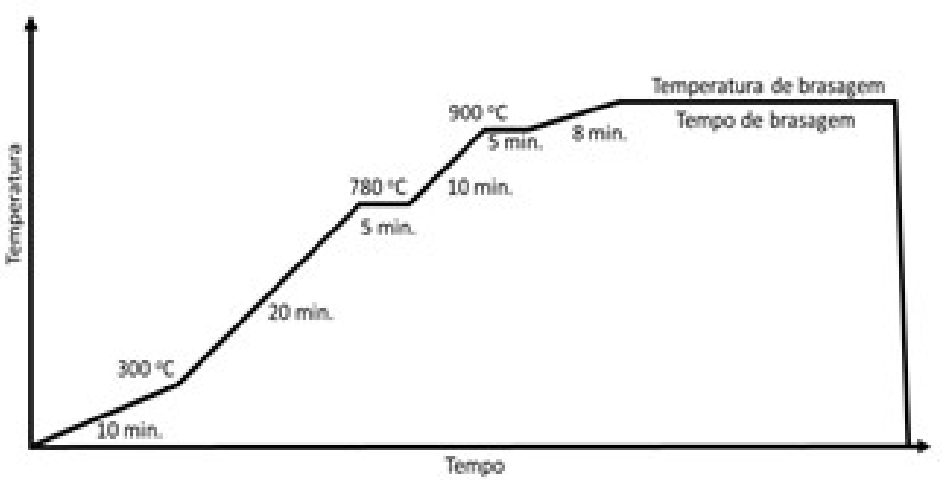

Figura 2. Ciclo térmico em forno a vácuo.

Para investigar a junta, as amostras foram seccionadas longitudinalmente e embutidas em baquelite.

$\mathrm{O}$ ataque foi feito por 60 segundos em temperatura ambiente com solução ácida - ácido pícrico (13,46 g/L), ácido clorídrico $(38,46 \mathrm{~mL} / \mathrm{L})$ e álcool etílico como diluente.

Utilizou-se equipamento de ensaio de tração Galdabini Quasar 100 para caracterizar a resistência das juntas. A máquina possui capacidade de $100 \mathrm{kN}$ e a velocidade praticada para ensaio foi de $0,6 \mathrm{~mm} / \mathrm{min}$ à temperatura ambiente.

As juntas brasadas ainda foram caracterizadas por medição de dureza Rockwell C com durômetro Mitutoyo HR-100 e microdureza Vickers em microdurômetro Shimadzu HMV-2000 com carga de $50 \mathrm{~g}$.

\section{Resultados e Discussões}

\subsection{Microscopia óptica}

Antes de proceder à análise mais detalhada, fez-se uma avaliação preliminar das juntas com microscópio óptico. A Figura 3 mostra que a maior parte da junta é composta por uma estrutura dendrítica muito similar a estrutura do metal de adição puro.

Próximos aos metais base, outros constituintes precipitados precisam de análises mais aprofundadas a fim de serem caracterizados.

Comparou-se a interface entre MA/EImax com a interface MA/DIN EN 1.4110 a fim de verificar se houve diferença entre elas devido a diferente composição química dos aços.

$\mathrm{Na}$ Figura 4a e b observa-se que há ligeira diferença no arranjo dos constituintes em contato com cada um dos metais base. A porção do MA que ficou em contato com o aço DIN EN 1.4110 possui o constituinte 1 mais contínuo e espesso, indicando que houve um bom molhamento (ou baixa energia de interface). Além disto, há nas áreas adjacentes porções grandes deste constituinte, similar a um crescimento colunar a partir da interface.

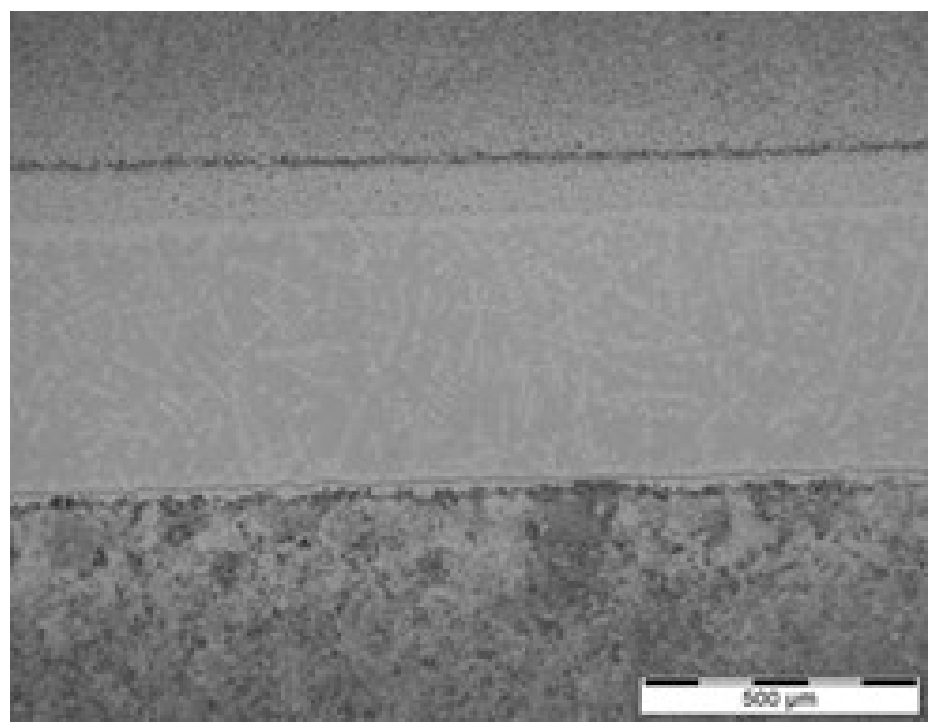

Figura 3. Microscopia óptica do CP 30.100.10. 


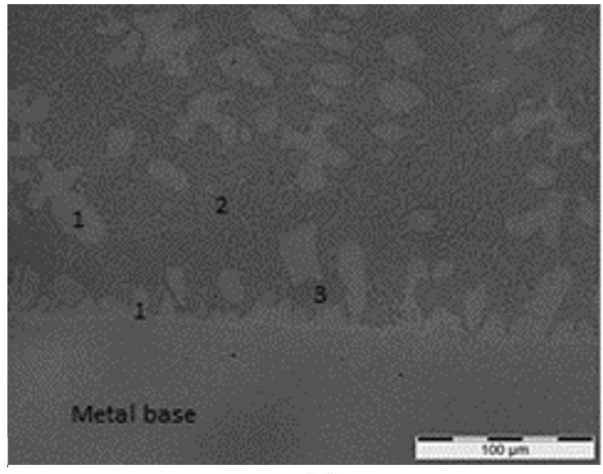

(a)

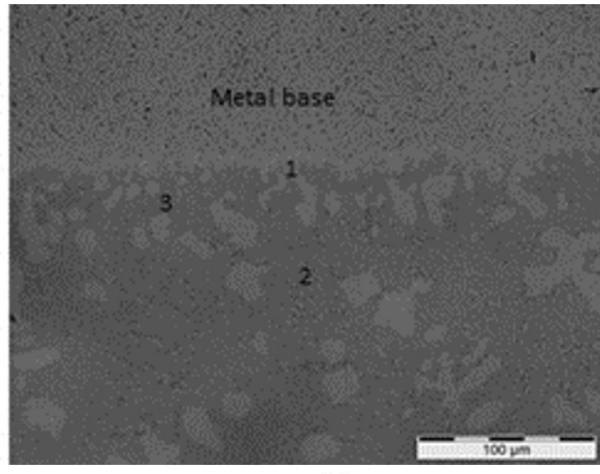

(b)

Figura 4. Microscopia óptica da interface MA/DIN EN 1.4110 (a) e Elmax/MA (b) - amostra 10.100.10 - constituinte 1 com Ni predominante (45\%), constituinte 3 de $\mathrm{Cr}$ predominante ( $\mathrm{Cr} 63 \%$ ) e constituinte 2 (composto pelos constituintes 1 e 3 ).

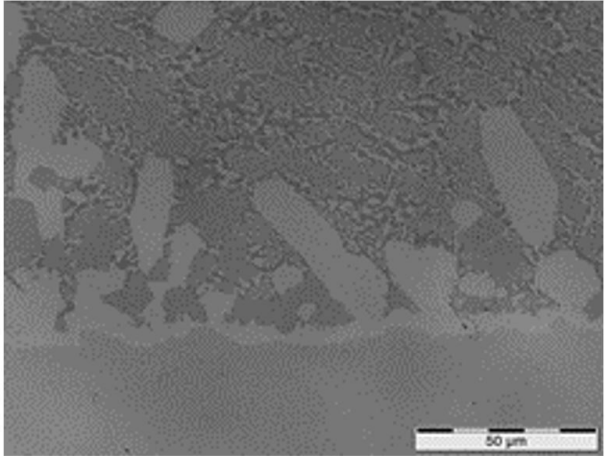

(a)

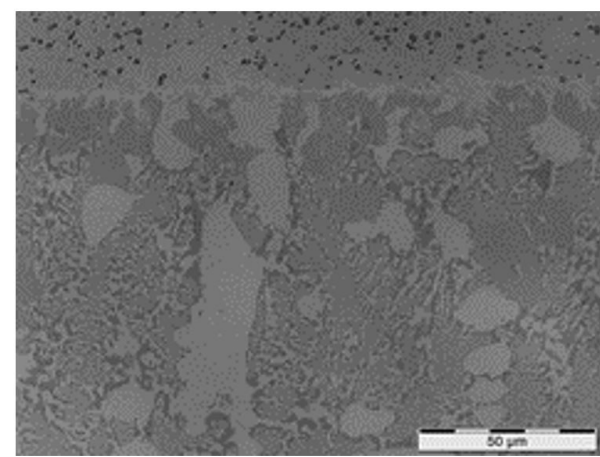

(b)

Figura 5. Microscopia óptica da interface MA/DIN EN 1.4110 (a) e Elmax/MA (b) - amostra 10.080.10.

Já na interface com o Elmax, a porção clara (constituinte 1) que fica preferencialmente em contato com o $\mathrm{MB}$ não é tão espessa, tampouco contínua. Houve uma predominância deste constituinte claro (1) na interface com o MB, porém irregular e interrompida frequentemente pelo constituinte escuro (3).

Outras amostras foram analisadas da mesma forma e o padrão se confirmou, como pode ser visto na Figura 5a, com a amostra 10.080.10, com uma maior ampliação a fim de detalhar a presença de cada um dos constituintes na interface.

Para avaliar o efeito da temperatura na junta, a Figura 6 ilustra a diferença entre a zona de transição MA/MB para as amostras brasadas a $1080{ }^{\circ} \mathrm{C}$ e $1120{ }^{\circ} \mathrm{C}$. Verifica-se na morfologia da região do $\mathrm{MA}$ a diferença entre as juntas brasadas a $1080^{\circ} \mathrm{C}$ e $1120^{\circ} \mathrm{C}$. Em ambas há uma faixa de transição entre o metal base e a zona dendrítica.

A morfologia de ambas amostras é similar, porém se verifica uma estrutura mais fina e homogênea na de mais baixa temperatura. Isto pode estar relacionado com a menor difusividade atômica na temperatura mais baixa. Para a temperatura de $1100{ }^{\circ} \mathrm{C}$ foi verificada uma condição intermediária entre as duas amostras da Figura 6.

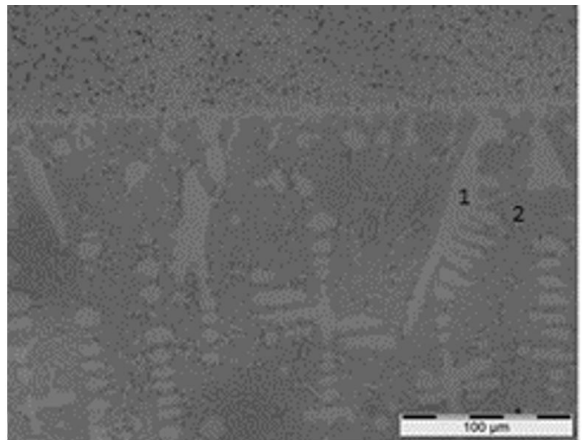

(a)

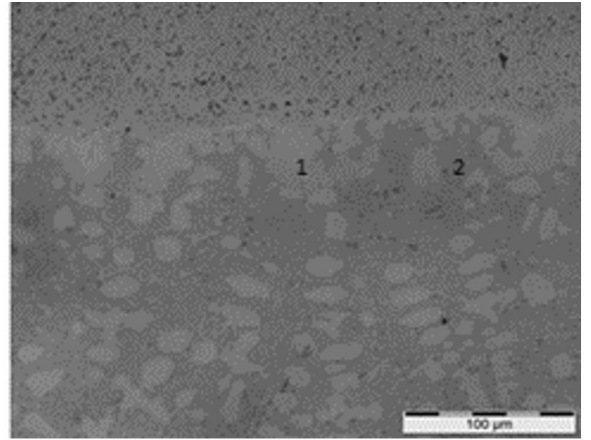

(b)

Figura 6. Microscopia óptica da interface Elmax/MA para as juntas brasadas a $1080^{\circ} \mathrm{C}$ (a) e $1120^{\circ} \mathrm{C}(\mathrm{b}$ - constituinte 1 (Ni predominante, aprox. $50 \%$ ), constituinte 2 (Cr predominante aprox.. $60 \%)$ ). 


\subsection{Análises por MEV}

Para melhor entender a composição e efeito de cada um dos constituinte na interface, foram executadas análises em MEV. Na Figura 7, as amostras foram dispostas de maneira a facilitar a comparação entre elas.

Percebe-se diferença entre os constituintes presentes em cada amostra, principalmente no que foi brasada a $1080{ }^{\circ} \mathrm{C}$. Para este, há 3 regiões de destaque, sendo uma região clara (1), uma escura (2) e uma matriz mesclada (3).

Após análise química feita por EDS, viu-se que a região 1, clara, é composta por aproximadamente $55 \%$ de níquel, 20\% de cromo e $15 \%$ de ferro. Pequenos percentuais de carbono e silício também foram encontrados.

A região escura (2) é composta basicamente por $45 \%$ de cromo, $30 \%$ de níquel, $6 \%$ de ferro e quantidades menores de carbono e silício.

O constituinte mesclado (3) é composto, em média, por $45 \%$ de níquel, $25 \%$ de cromo, 20\% de ferro, contendo ainda silício e fósforo em pequenas quantidades.

As amostras brasadas em temperaturas mais altas apresentam estrutura mais complexa. Um constituinte bem claro (1), possui as mesmas características descritas anteriormente para a mostra 10.080.10. Observa-se ainda na microscopia um constituinte um pouco mais escuro (2), também de características similares às já descritas anteriormente.

Um constituinte ainda mais escuro, (4) pode ser identificado. Segundo a análise por EDS, este constituinte muito escuro é composto aproximadamente por $55 \%$ de cromo, $22 \%$ de níquel, $12 \%$ de ferro e $10 \%$ de carbono.

Uma segunda comparação foi feita entre as amostras utilizando as micrografias eletrônicas na Figura 8.

Comparando-se as micrografias e o efeito do tempo na junta, observa-se que 5 minutos é um tempo muito curto para formação dos constituinte presentes nas demais amostras. Apesar da brasagem ter ocorrido com sucesso, não houve difusão suficiente para que se formassem os constituintes presentes nas demais condições.

$\mathrm{Na}$ amostra mantida em temperatura por 30 minutos é possível verificar uma estrutura complexa como na amostra 10.120.10, discutida anteriormente. Os mesmos constituintes estão presentes. É possível notar, porém, que para o constituinte mais escuro ( 5 e 6 , rico em cromo), existem alguns pontos com formato mais esférico, enquanto outros pontos de mesma cor possuem formas com ângulos mais agudos. Desta forma, foi feita a análise com EDS para verificar possíveis diferenças químicas entre estas duas regiões, resultados na Tabela 3.

Ainda, com base nos resultados dos testes de tração, estes constituintes de maior dureza podem ter efeito positivo na resistência a tração, reforçando a junta.

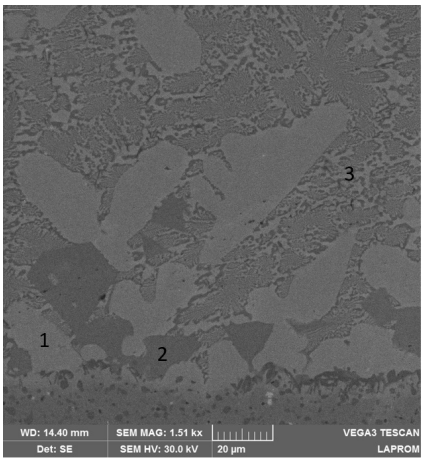

10.080.10

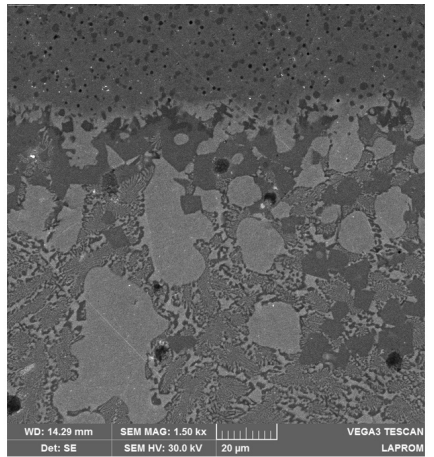

10.100.10

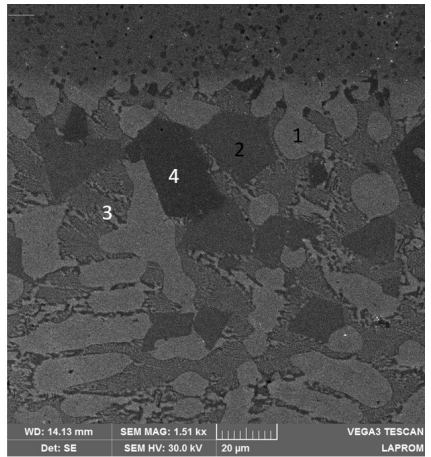

10.120 .10

Figura 7. Efeito da temperatura; microscopia eletrônica de varredura (MEV) das regiões interfaciais entre metal de adição/metal base para diferentes amostras - constituintes 1 (Cr 52 \%; Ni $24 \%), 2$ (Cr $45 \%$, Ni $36 \%), 3$ (Ni $45 \%$, Cr $24 \%$ ) e 4 (Cr $96 \%$, Fe $4 \%$ ).

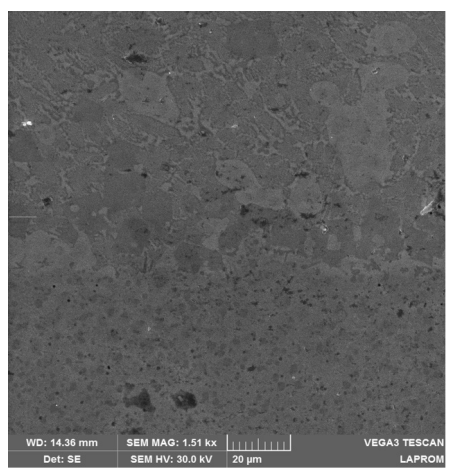

5.100 .10

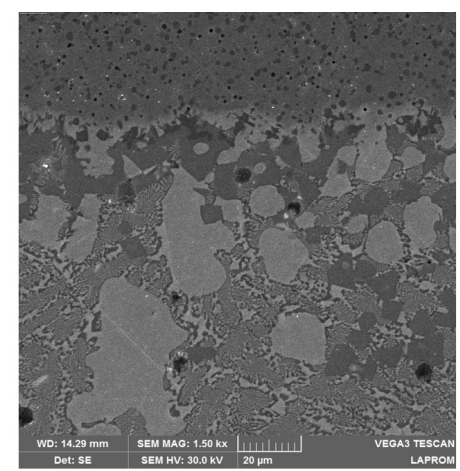

10.100.10

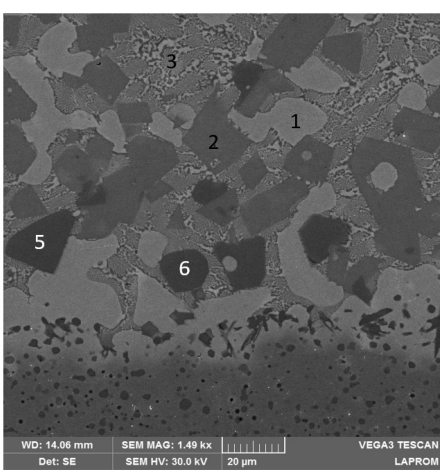

30.100 .10

Figura 8. Efeito do tempo; microscopia eletrônica de varredura (MEV) das regiões interfaciais MA/MB para diferentes amostras. 
Tabela 3. Composição química para os diferentes constituintes da amostra 30.100.10.

\begin{tabular}{|c|c|c|c|}
\hline Região Pontiaguda (5) & 30.100 .10 & Região esférica (6) & 30.100 .10 \\
\hline Elemento & Peso [\%] & Elemento & Peso [\%] \\
\hline $\mathrm{Cr}$ & 63,76 & $\mathrm{Cr}$ & 54,18 \\
\hline $\mathrm{Ni}$ & 13,97 & $\mathrm{Ni}$ & 22,31 \\
\hline $\mathrm{Fe}$ & 8,55 & $\mathrm{Fe}$ & 12,03 \\
\hline $\mathrm{C}$ & 11,59 & $\mathrm{C}$ & 10,03 \\
\hline
\end{tabular}

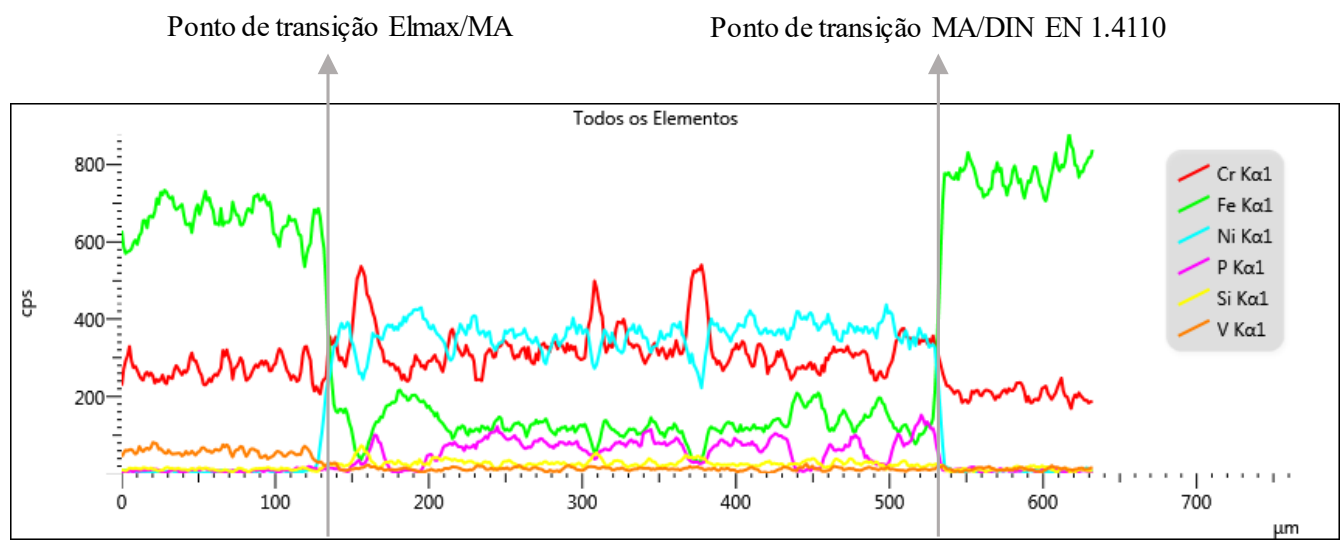

Figura 9. MEV - perfil de composição química da junta brasada no CP 10.100 .10 a fim de verificar a extensão das áreas de transição metal base/meta de adição/metal base.

Fez-se também uma varredura do perfil de composição química através do EDS para as duas amostras de forma a analisar todo a seção transversal da região brasada e confirmar as informações levantadas com microscopia óptica e MEV. Para diversas amostras o perfil da curva foi similar, de forma que apenas a curva da amostra 10.100.10 é representada na Figura 9.

Não se percebe grande difusão e elementos para o interior dos materiais base, tampouco uma grande diluição dos metais base para o interior do metal de adição. A maior diluição que houve foi para o ferro, que esteve presente ao longo de toda a junta. Como a pasta de brasagem não contém este elemento, todo o ferro contido na junta vem da difusão. Este teor do metal em questão foi maior conforme maior foi a temperatura e tempo pra difusão, variando desde $5 \%$ para a amostra 5.100 .10 até teores acima de $20 \%$ para as amostras de 30 minutos.

Através do perfil de composição química se observa os intervalos da junta bem definidos, com interfaces entre MA e MB ocupando uma pequena distância.

Observa-se ainda na Figura 9 que a folga evidenciada pelos pontos de transição entre os materiais é maior que os 0,10 mm anteriormente propostos. Esta diferença possivelmente se dá devido aos materiais base serem martensíticos e o suporte de brasagem austenítico. Assim, quando ultrapassam a temperatura de austenitização dos $\mathrm{MB}$, apenas estes reduzem seu tamanho (aumentando a folga). Durante o resfriamento a folga já está preenchida pelo MA sólido e não mais se reduz ao tamanho original.

\subsection{Análise de microdureza Vickers}

A Figura 10 mostra a microdureza encontrada para os diferentes constituintes da junta.

É possível diferenciar duas partes distintas no interior da junta: um constituinte mais claro e menos duro disperso em uma matriz mesclada predominante e de dureza mais elevada. A dureza do constituinte claro é cerca de $500 \mathrm{HV}$, enquanto o constituinte mesclado, possui dureza média de $786 \mathrm{HV}$.

Ainda, mediu-se um ponto no metal base contendo um constituinte também claro, possivelmente o mesmo constituinte de baixa dureza que aparece no centro da junta. A dureza deste ponto é de $390 \mathrm{HV}$. 


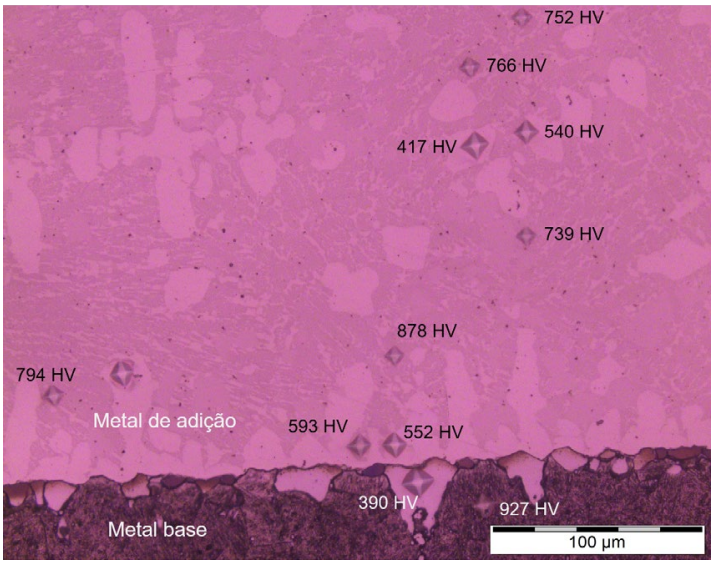

Figura 10. Imagem da medição de microdureza Vickers para constituinte da junta brasada a $1080^{\circ} \mathrm{C}$

Os metais base também foram medidos. Foi medido no DIN EN 1.4110 um ponto com microdureza 927 HV, indicando que possivelmente o ponto medido coincide com um carboneto ou constituinte frágil formado na brasagem. Demais medições neste aço resultaram em 568 HV. A microdureza do aço Elmax é de 633 HV.

\subsection{Efeito do tempo sobre as propriedades mecânicas das juntas brasadas}

O efeito do tempo sobre as propriedades mecânicas das juntas brasadas foi avaliado em teste de tração. Para estes corpos de prova, o aquecimento em forno a vácuo foi mantido com os mesmos parâmetros, mas o tempo de permanência no patamar máximo de temperatura foi alterado. Para uma folga de $0,10 \mathrm{~mm}$, foram brasadas juntas com 5,10 e 30 minutos de permanência a $1100{ }^{\circ} \mathrm{C}$.

Apesar de haver uma variação entre os CP, a Figura 11 mostra que as amostras de 5 minutos de patamar obtiveram a menor resistência, com uma média de $7228 \mathrm{~N}$. As amostras brasadas por 10 minutos atingiram os valores mais altos, obtendo $11166 \mathrm{~N}$, um incremento de 54\%. Para tempos maiores, 30 minutos, os resultados foram intermediários: $9893 \mathrm{~N}$.

Esta queda de resistência entre as amostras de 10 e 30 minutos pode estar relacionada com a formação de compostos intermetálicos frágeis, o que deve ser evidenciado pela análise através de MEV.

\subsection{Efeito da temperatura sobre as propriedades mecânicas das juntas brasadas}

Os CP brasados nas temperaturas de 1080,1100 e $1120^{\circ} \mathrm{C}$ (todos durante $10 \mathrm{~min}$ ) foram submetidos a ensaio de tração. A Figura 12 mostra os valores obtidos neste ensaio.

Analisando os gráficos percebe-se que um aumento da temperatura leva a um aumento na tensão máxima de ruptura da junta.

Para a amostra brasada a $1080{ }^{\circ} \mathrm{C}$ o valor médio de tensão de ruptura ficou em $8162 \mathrm{~N}$, subindo para $11166 \mathrm{~N}$ para a condição de $1100{ }^{\circ} \mathrm{C}$. Os maiores valores são para a amostra processada a $1120^{\circ} \mathrm{C}$, que atingiu $11759 \mathrm{~N}$ de média para os 3 corpos de prova, um aumento de $44 \%$ em relação a condição de $1080^{\circ} \mathrm{C}$.

A fim de melhor compreender a influência da temperatura na junta brasada, analisou-se em microscópio óptico a região do MA com os MB.

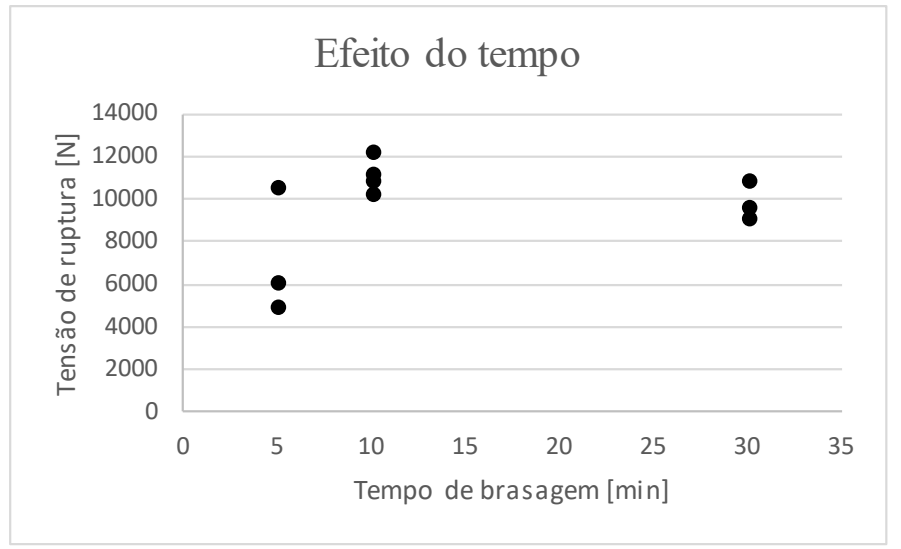

Figura 11. Efeito do tempo de brasagem na temperatura de $1100^{\circ} \mathrm{C}$ sobre a resistência à tração da junta. 


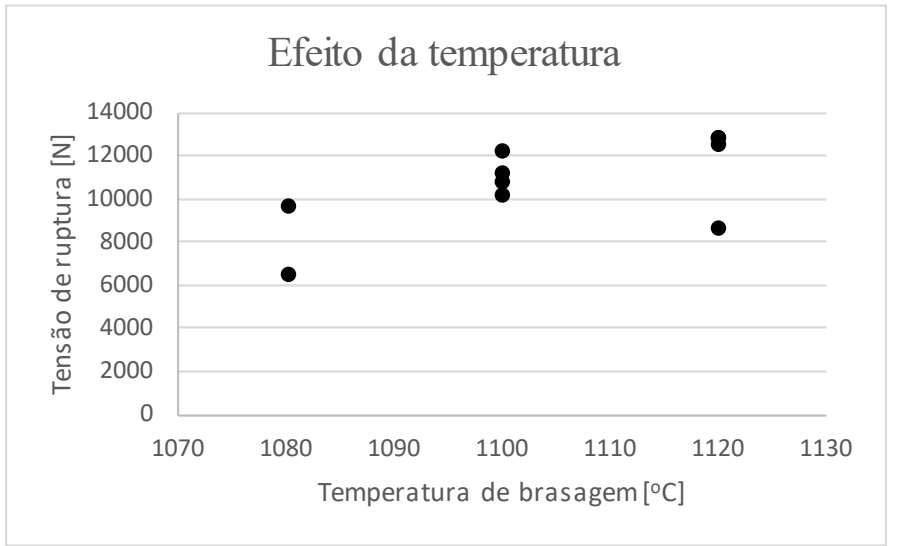

Figura 12. Efeito da temperatura na brasagem no tempo de 10 minutos sobre a resistência à tração da junta.

\section{Conclusões}

a) É possível brasar os aços inoxidáveis martensíticos DIN EN 1.4110 e Uddeholm Elmax com metal de adição na forma de pasta B-Ni60CrPSi-980/1040 (DIN EN ISSO 3677). O forno a vácuo se mostrou um equipamento adequado para este processo;

b) A têmpera dos materiais base juntamente com a brasagem não se mostrou um impedimento para a adequada operacionalização do processo;

c) Há notável influência das condições de brasagem sobre a resistência à tração da junta. Para a folga de 0,10 mm, as condições que produziram junta com maior resistência à tração foram tempo de 10 minutos e temperatura de $1120^{\circ} \mathrm{C}$.

\section{Agradecimentos}

Entre todos que contribuíram para este trabalho, agradecimentos à Tramontina S/A Cutelaria pela disponibilização de sua estrutura, especialmente para equipe do Laboratório e ao Gerente Técnico André Cousandier Galant.

À Profa. Dra. Gelsa Edith Navarro Hidalgo, do LAPROM - UFRGS, pela obtenção das imagens de MEV.

\section{Referências}

[1] Totten GE, Howes MAH. Steel heat treatment handbook. 1st ed. New York: Marcel Dekker; 1997.

[2] Brossa M, Guerreschi U. Effects induced by the brazing thermal cycle on the structural properties of materials in steel brazed joints. Journal of Nuclear Materials. 1988;157:626-630. http://dx.doi.org/10.1016/0022-3115(88)90385-6.

[3] Gangadharan S, Sivakumar D, Venkateswaran T, Kulkarni K. Evolution of microstructure in brazed joints of austenitic-martensitic stainless steel with pure silver obtained with Ag-27Cu-5Sn Brazing filler material. Metallurgical and Materials Transactions A, Physical Metallurgy and Materials Science. 2016;47(12):6148-6159. http://dx.doi.org/10.1007/s11661-016-3787-x.

[4] Zhang WW, Cong S, Huang Y, Tian YH. Micro structure and mechanical properties of vacuum brazed martensitic stainless steel/tin bronze by Ag-based alloy. Journal of Materials Processing Technology. 2017;248:64-71. http://dx.doi.org/10.1016/j.jmatprotec.2017.05.018.

[5] Yulong L, Cheng Z, Xiaowu H, Jicai F, Peng H. Mechanism and process of the intermetallic compound particles reinforced TiAl/steel brazing seam. Rare Metal Materials and Engineering. 2015;44(9):2086-2090. http://dx.doi.org/10.1016/S1875-5372(16)30002-9.

[6] Jiang W, Gong J, Tu ST. Effect of brazing temperature on tensile strength and microstructure for a stainless steel plate-fin structure. Materials \& Design. 2011;32(2):736-742. http://dx.doi.org/10.1016/j.matdes.2010.07.032.

[7] Koster M, Lis A, Lee WJ, Kenel C, Leinenbach C. Influence of elastic - plastic base material properties on the fatigue and cyclic deformation behavior of brazed steel joints. International Journal of Fatigue. 2016;82:49-59. http://dx.doi.org/10.1016/j.ijfatigue.2015.07.029.

[8] Zheng Y, Li N, Yan J, Cao Y. The microstructure and mechanical properties of 1Cr17Ni2/QAl7 brazed joints using Cu-Mn-Ni-Ag brazing alloy. Materials Science and Engineering A. 2016;661:25-31. http://dx.doi.org/10.1016/j.msea.2016.03.020.

[9] Cai Q, Liu W, Ma Y, Liu H. Microstructure, residual stresses and mechanical properties of diffusion bonded tungsten-steel joint using a V/Cu composite barrier interlayer. International Journal of Refractory Metals \& Hard Materials. 2015;48:312-317.

http://dx.doi.org/10.1016/j.ijrmhm.2014.09.002. 
[10] Cai Q, Liu W, Ma Y, Wang Z. Diffusion brazing of tungsten and steel using Ti-Ni liquid phase forming interlayer. Fusion Engineering and Design. 2015;91:67-72. http://dx.doi.org/10.1016/j.fusengdes.2014.12.029.

[11] Ruiz-Vargas J, Siredey-Schwaller N, Gey N, Bocher P, Hazotte A. Microstructure development during isothermal brazing of Ni/BNi-2 couples. Journal of Materials Processing Technology. 2013;213(1):20-29. http://dx.doi.org/10.1016/j.jmatprotec.2012.07.016.

[12] Ou C, Liaw DW, Du YC, Shiue RK. Brazing of 422 stainless steel using the AWS classification BNi-2 Braze alloy. Journal of Materials Science. 2006;41(19):6353-6361. http://dx.doi.org/10.1007/s10853-006-0709-0.

[13] Chakraborty G, Chaurasia PK, Murugesan S, Albert SK, Murugan S. Effect of brazing temperature on the microstructure of martensitic austenitic steel joints. Materials Science and Technology. 2017;836(11):1-7. http://dx.doi.org/10.1080/02670836.2017.1292205.

[14] Venkateswaran T, Xavier V, D S, Pant B, G.D JR. Brazing of stainless steels using Cu-Ag-Mn-Zn braze filler: studies on wettability, mechanical properties, and microstructural aspects. Materials \& Design. 2017;121:213-228. http://dx.doi.org/10.1016/j.matdes.2017.02.057.

[15] Beura VK, Xavier V, Venkateswaran T, Kulkarni KN. Interdiffusion and microstructure evolution during brazing of austenitic martensitic stainless steel and aluminum-bronze with Ag-Cu-Zn based brazing filler material. Journal of Alloys and Compounds. 2018;740(5):852862. http://dx.doi.org/10.1016/j.jallcom.2018.01.043.

[16] Schwartz MM. Brazing. 2nd ed. Materials Park: ASM International; 2003.

[17] Machado IG. Soldagem e técnicas conexas: processos. Porto Alegre: Associação Brasileira de Soldagem; 1996.

[18] Tillmann W, Henning T, Boretius M. Effect of the dwell time on the microstructure and tensile strength of vacuum - brazed tool steels using BNi-2 filler metal. Welding in the World. 2019;63(5):1477-1488. http://dx.doi.org/10.1007/s40194-019-00734-z.

[19] Winiowski A, Rózanski M. Impact of tin and nickel on the brazing properties of silver filler metals and on the strength of brazed joints made of stainless steels. Archives of Metallurgy and Materials. 2013;58(4):1007-1011. http://dx.doi.org/10.2478/amm-2013-0118.

[20] Elrefaey A, Tillmann W. Brazing of titanium to steel with different filler metals : analysis and comparison. Journal of Materials Science. 2010;45(16):4332-4338. http://dx.doi.org/10.1007/s10853-010-4357-z.

[21] Jiang C, Chen H, Wang Q, Li Y. Effect of brazing temperature and holding time on joint properties of induction brazed WC-Co/carbon steel using Ag-based alloy. Journal of Materials Processing Technology. 2016;229:562-569. http://dx.doi.org/10.1016/j.jmatprotec.2015.09.044.

[22] Lugscheider E, Reimann H, Knotek O. Calculation of strength of single-lap shear specimen. Weld. Res. 1977;(Suppl.): 189s-192s.

[23] Lugscheider E, Partz KD. High temperature brazing of stainless steel with nickel-base filler metals BNi-2, BNi-5 and BNi-7. Welding Research. 1983:160-164.

[24] Dai X, Cao J, Liu J, Su S, Feng J. Effect of holding time on microstructure and mechanical properties of SiC/SiC joints brazed by Ag-Cu-Ti + B4C composite filler. Materials \& Design. 2015;87:53-59. http://dx.doi.org/10.1016/j.matdes.2015.08.020.

[25] Fontargen. In-dept know how. 2018 [acesso em 1 set. 2019]. Disponível em: https://www.voestalpine.com/welding/es/content/download/9991/183893/file/FON_HTL+5+CR_EN_2018_GL_105_Preview.pdf 